\title{
KONTRASTIVITAS DIATESIS PASIF BAHASA INDONESIA DAN BAHASA JEPANG DALAM DONGENG JEPANG MOMOTARŌ
}

\author{
Luh Putu Ratnayanti Sukma \\ LPK LPJ Bali \\ puturatnays@gmail.com \\ Luh Gde Intan Purnama Sari Setiawan \\ Triton Denpasar \\ iiintanpurnama88@gmail.com
}

\begin{abstract}
ABSTRAK
Penelitian ini bertujuan untuk (1) mendeskripsikan aturan bentuk pasif dalam bahasa Indonesia dan Jepang, (2) menemukan penanda kalimat pasif dalam bahasa Indonesia dan Jepang, (3) mendeskripsikan persamaan dan perbedaan kalimat pasif dalam bahasa Indonesia dan Jepang. Data dikumpulkan dengan metode deskriptif. Metode analisis kontras digunakan dalam analisis data. Hasil analisis data disajikan dengan metode Pemasifan Indonesia yang dijelaskan oleh perubahan morfologi pada kata kerja, misalnya bahasa Indonesia pasif menggunakan penanda di-, ter- dan kean. Sementara itu, pemasifan bahasa Jepang digambarkan oleh kata kerja dan kata benda yang berfungsi sebagai objek dalam kalimat pasif. Kata kerja Jepang terdiri dari kata kerja konsonan, kata kerja vokal, dan kata kerja tidak beraturan. Kalimat pasif dalam bahasa Jepang ditandai oleh: marker $n i+V$-areru untuk kata kerja konsonan, marker $n i+V$-areru untuk kata kerja vokal, $n i+V$-areru untuk kata kerja tidak beraturan, dan $n i+$ yotte $V$-areru / V-rareru untuk kata kerja yang diikuti a benda mati. Di samping itu, ada dua pemasifan dalam bahasa Jepang: pemasifan menggunakan objek langsung dan objek tidak langsung. Akan tetapi, pemasifan bahasa Jepang secara tidak langsung dapat menggunakan kata kerja transitif atau kata kerja intransitif. Kalimat pasif Jepang mengungkapkan penyelesaian suatu tindakan dan makna yang tidak menyenangkan. Sebagai perbandingan, kalimat pasif bahasa Jepang tidak digunakan secara teratur seperti kalimat pasif bahasa Indonesia karena kalimat pasif bahasa Jepang cenderung mengekspresikan sudut pandang orang pertama. Selain itu, perbedaan lain antara kalimat pasif dalam bahasa Indonesia dan Jepang adalah bahwa dalam bahasa Jepang penting untuk mengetahui siapakah subjeknya.
\end{abstract}

Kata kunci: bahasa; budaya; makna

\begin{abstract}
This study aims at (1) describing the rules of the passive voice in Indonesian and Japanese languages, (2) finding the markers of passive sentences in Indonesian and Japanese languages, (3) describing the similarities and differences of passive sentences in Indonesian and Japanese. The data is collected by the descriptive method. The method of data analysis is a contrastive analysis. The result of data analysis is presented by method Indonesian passivization explained by the change of morphology on the verb, for example, Indonesian language passive using markers di-, ter-and ke-an. Meanwhile, Japanese language passivization is described by verbs and nouns functioning as objects in passive sentences. Japanese verbs consist of consonant verbs, vowel verbs, and irregular verbs. Passive sentences in the Japanese language are marked by marker $n i+V$-areru for consonant verbs, markers $n i+V$-areru for vocal verbs, $n i+V$-areru for irregular verbs, and $n i+$ yotte $V$ areru/V-rareru for verbs that are followed as object inanimate nouns. Similarly, there are two passivizations in Japanese: passivization using the direct object and the indirect object. However, the indirect passivization of the Japanese can use transitive verbs or intransitive verbs. Japanese passive sentences express the completion of an action and an unpleasant meaning. In comparison, the Japanese passive sentence is not used as regularly as Indonesian passive because Japanese
\end{abstract}


KONTRASTIVITAS DIATESIS PASIF BAHASA INDONESIA DAN BAHASA JEPANG ...

passive tends to express a point of view first person. In addition, another difference between passive sentences in Indonesian and Japanese is that in Japanese it is important to know the subject.

Keywords: language; culture; meaning

\section{PENDAHULUAN}

Setiap bahasa memiliki ciri khasnya masing-masing yang membuat suatu bahasa berbeda dengan bahasa lainnya. Bermacammacam ciri bahasa yang dapat dimunculkan oleh suatu bahasa dapat terlihat dari segi struktur semantik, sintaksis, morfologi, dan lainnya. Salah satu ciri bahasa yang dilihat dari sisi sintaksis selalu memuat hal-hal yang berkaitan dengan kelas kata seperti nomina, verba, ajektiva, adverbial, adposisi (preposisi atau posposisi), dan lain sebagainya (Verhaar, 1996: 170) Salah satu kategori sintaksis yang dapat mengalami perubahan bentuk yaitu verba. Perubahan bentuk pada kelas kata verba bersifat structural. Salah satu sifat verba yang dapat memengaruhi makna serta fungsi sebuah kalimat verbal biasanya disebut dengan istilah diatesis. Dalam istilah lainnya, diathesis dikenal juga dengan istilah voice. Lebih lanjut, voice dijelaskan sebagai kategori makna (meaning categories) yang menunjukan adanya relasi antara pelaku atau partisipan dengan verba. Indikasi adanya voice dalam sebuah kalimat dapat terlihat pada sistem afiks verbal atau kelas kata lainnya, selain tentunya dapat juga dilihat dari hubungan sintaktis antara verba tersebut. Acuan struktur diathesis sebuah kalimat atau klausa adalah struktur kalimat atau klausa itu sendiri yang dilihat dari sisi valensi (valency). Valensi adalah relasi sintaktis antara verba dan unsur lain di sekitarnya, misalnya relasi antara verba dengan partisipan atau agent dalam kalimat tersebut.

Pembahasan tentang diatesis atau voice dapat dijabarkan dengan beberapa jenis seperti, (a) diatesis aktif, jika subjek berperan menjadi pelaku perbuatan; (b) diatesis pasif, jika subjek menjadi sasaran dari perbuatan; (c) diatesis refleksif, jika subjek mengenakan perbuatan pada dirinya sendiri; (d) resprokal, jika subjek jamak saling mengenai perbuatan atau berbalasan; (e) kausatif, jika pelaku terkena keadaan atau kejadian; (f) benefaktif, jika pelaku beraksi untuk orang lain (Elson and Pickett, 1962:24).
Dalam artikel ini, diatesis yang akan dibahas adalah diatesis pasif dengan melihat kontrastivitas pada bahasa Indonesia dengan bahasa Jepang. Bahasa Indonesia dan bahasa Jepang merupakan bahasa dalam rumpun yang berbeda, maka dari itu perbedaan diantara keduanya dapat dilihat dari berbagai sudut pandang. Namun, di setiap perbedaan terdapat juga kemungkinan adanya kesamaan, sehingga analisis kontrastif kedua bahasa ini ditilik dari diatesis pasif merupakan hal yang menarik untuk dibahas secara mendalam. Teori yang digunakan yaitu Ukemi oleh Iori (2001) dan Konstruksi Pasif oleh Alwi, et al (1998).

\section{METODE}

Setiap karya ilmiah yang dibuat disesuaikan dengan metodologi penelitian. Ditinjau dari jenis datanya, pendekatan penelitian yang digunakan dalam artikel ini adalah pendekatan kualitatif. Penelitian kualitatif bermaksud untuk memahami fenomena tentang sesuatu yang dialami oleh subjek penelitian secara holistic, secara deskriptif dalam bentuk kata-kata dan bahasa, pada suatu konteks khusus yang alamisah dan dengan memanfaatkan berbagai metode ilmiah (Moleong, 2007).

Data primer dalam penelitian ini adalah kalimat-kalimat pasif baik dalam bahasa Indonesia ataupun bahasa Jepang yang ditemui dalam cerita rakyat momotaro beserta terjemahannya dengan menggunakan metode simak dan teknik catat. Selanjutnya data dianalisis secara kualitatif dengan metode agih dimana alat penentu untuk menganalisis data merupakan bagian dari bahasa itu sendiri seperti kata, fungsi sintaksis, klausa, dsb (Sudaryanto, 1993: 18-19).

\section{PEMBAHASAN \\ Konstruksi Diatesis Pasif}

Konstruksi pasif adalah bentuk konstruksi yang dalam polanya unsur subjek berperan sebagai pasien (sasaran). Suatu kalimat dapat dikatakan sebagai kalimat pasif jika partisipan 
dalm kalimat tersbut memiliki informasi lama yang tampak pada struktur batinnya (deep structure). Dalam konstruksi pasif, partisipan menjadi patient atau sasaran dari verba.

\section{Diatesis Pasif Bahasa Indonesia}

Struktur kalimat dalam bahasa Indonesia adalah SPO. Konstruksi pasif bahasa Indonesia belum menemukan titik temu yang sama antara para linguis akan jumlah maupun bentuknya. Terdapat tiga bentuk kalimat pasif, yaitu pasif $d i-$, pasif ter-, dan pasif ke-an (Alisjahbana, 1983). Sedangkan, Mees berpendapat bahwa bentuk pasif bahasa Indonesia terdiri dari tiga bentuk, yaitu pasif $d i$-, pasif ter-, pasif ke-an, dan pasif orang pertama dan orang kedua (Mees, 1969). Selain itu, yang membagi bentu pasif ke- menjadi lima jenis, yaitu pasif berpelaku, pasif bantuan, pasif umum, pasif keadaan, dan pasif turunan (Slametmuljana, 1969).

Secara keseluruhan, perbedaan pendapat tentang bentuk dan jumlah pasti konstruksi pasif dalam bajasa Indonesia dapat merujuk pada satu kesamaan yaitu ciri umum kalimat pasif dalam bahasa Indonesia biasanya menggunakan awalan di-, ter-, dan ke-. Di samping itu, penggunaan semantic approach sebagai kriteria utama dan afiks verbal dengan kriteria tambahan, Dardjowidjojo dalam Purwo (1986) mengklasifikasi konstruksi pasif bahasa Indonesia menjadi empat jenis, yakni (1) jenis yang menyatakan kesengajaan, (2) jenis yang menunjukkan perbuatan yang tak disengaja, (3) jenis yang menunjukkan adversatif, dan (4) jenis yang menyatakan dapat $d i$ -

Sebuah verba dalam konstruksi pasif umumnya ditandai dengan adanya prefiks $d i$ untuk jenis kalimat pasif yang menyatakan kesengajaan suatu perbuatan (Dardjowidjojo, 1986). Selain itu, penderita dalam konstruksi pasif juga biasanya diletakkan di depan verba, tetapi jika pelaku perbuatan dipisahkan dari verba oleh unsur lainnya, pelaku itu harus didahului pemarkah oleh dengan syarat pemarkah dan pelakunya adalah manusia. Berikut merupakan contoh kalimat pasif dalam bahasa Indonesia yang ditemukan dalam terjemahan cerita rakyat Jepang Momotaro.

\section{Analisis Konstruksi Pasif Bahasa Indonesia}

Berikut merupakan data yang diperoleh dari buku dongeng momotaro terjemahan bahasa Indonesia.

1. Jika Momotaro diberi semangkuk nasi, dia akan makan semangkuk juga.

2. Kemudian, jika dia diajari berhitung satu, maka dia dapat berhitung dari satu sampai sepuluh.

3. Tidak lama berselang Momotaro dibuatkan bekal kibidango terenak di Jepang.

4. Lalu, punggungnya dipasangkan bendera bertuliskan 'Momotaro yang terkuat nomor satu di Jepang'.

5. Siluman itu dipukul-pukul.

6. Siluman kedatangan seseorang yang tak dikenalnya.

7. Seluruh benda-bendaa milikku yang berharga ini kuserahkan padamu.

8. Buah momo itu terbawa arus sungai dan ditemukan oleh seorang nenek yang sedang mencuci

Verba pasif kanonis dalam Bahasa Indonesia ditandai dengan adanya pemarkah berupa afiks di-, ter-, dan ke-an. Afiks didalam temuan contoh data di atas dapat berkombinasi dengan sufiks - $i$ dan -kan yang seperti yang terlihat pada kalimat 2, 3, 4, dan 8 . Kalimat 1 merupakan konstruksi pasif kanonis yang berasal dari verba ditransitif yaitu beri. Bentuk oleh pada kalimat tersebut bersifat manasuka sehingga dapat aja dihilangkan. Hal tersebut terjadi karena kata 'oleh' merupakan non-core argument, sehingga, kalimat 1 mengalami penurunan valensi di dalam kalimat pasifnya. Kalimat 2, verba diajari berasal dari kata dasar ajar dengan penambahan prefiks $d i$ dan sufiks $-i$.

Pada kata dibuatkan dan dipasangkan terdapat makna benefaktif karena objek mendapatkan keuntungan. Verba dibuatkan dan dipasangkan berasal dari kata buat dan pasang dengan menambahkan konfiks di-kan yang berbeda dengan prefiks $d i$ - berakhiran sufiks $-i$. Adanya penambahan sufiks -kan membuat konstruksi pasif tersebut memiliki makna membawa keuntungan bagi orang lain, atau dengan kata lain ada yang mendapatkan keuntungan atas hadirnya verba tersebut. Kata dibuatkan dan dipasangkan memiliki objek langsung yaitu bekal kibi dan bendera. Namun pada contoh diatas, kalimat tersebut 
menghilangkan agen dari kegiatan verba tersebut dengan ketiadaan bentuk oleh.

Contoh 5 pada data dengan verba 'dipukulpukul' menunjukkan adanya bentuk pasif dalam bahasa Indonesia dengan pengulangan verba untuk membuat makna berulang-ulang sedangkan pada contoh 6 bentuk pasif dengan imbuhan $k e-$-an menunjukkan adanya verba pasif yang menunjukkan bahwa bentuk tersebut tidak dapat diubah menjadi verba aktif, serta subjeknya berperan sebagai penanggap yaitu yang merasakan, mengalami, dan menderita. Tetapi pada konstruksi pasif contoh ini merupakan bentuk pasif non kanonis dimana tidak ada penanda subjek di depan verbanya. Berbeda hal nya dengan bentuk pasif pada contoh 7 yang menempatkan pronomina 'ku' sebagai bentuk pasif. Kalimat tersebut bila diubah dalam bentuk pasif dengan prefiks $d i$ akan menjadi semua barang-barang berharga ini diserahkan kepadamu oleh diriku. Argumen diriku mengalami perpindahan ke depan dengan memunculkan bentuk pronominal $k u$-. Selain imbuhan yang telah disebutkan diatas, ditemukan juga dalam cerita bentuk konstruksi pasif dengan prefiks ter- yang memiliki makna tidak sengaja sesuai pada contoh 8 .

\section{Diatesis Pasif bahasa Jepang}

Bahasa Jepang juga memiliki perubahan verba yang mengindikasikan bentuk pasif. Kalimat pasif dalam bahasa Jepang disebut dengan istilah ukemi. Struktur dan urutan kalimat bahasa Jepang terdiri dari subjek, objek dan predikat (S-O-P). Dalam bahasa Jepang diatesis pasif (Ukemi) dapat dilihat dengan adanya perubahan masing-masing golongan verba. Ada beberapa pola diatesis pasif dalam bahasa Jepang yang menandai diatesis pasif, yaitu dengan pemarkah $\{-$ are-(ru) $\}$ dan $\{-$ rare (ru) \} dan bentuk yang menempel pada verba sebagai sufiks (bentuk spesial). Berikut adalah penjelasan verba sesuai dengan golongan masing-masing.

1. Pola $\{$-are-(ru) $\}$ digunakan oleh verba golongan I, yaitu verba yang berakhiran \{bu, -gu, -ru, -su, -tsu, -mu, -nu, -u .

Contoh:

a. Tobu (tobimasu) 'terbang' - tobareru tobaremasu - tobaremasen b. Oyogu (oyogimasu) 'berenang' oyogareru - oyogaremasu oyogaremasen

2. Pola $\{$-rare (ru) $\}$ digunakan oleh verba golongan II, yaitu verba yang berakhiran \{eru dan -iru\}.

Contoh :

a. Taberu (tabemasu) 'makan' taberareru - taberaremasu taberaremasen

b. Kiru (kimasu) 'memakai (pakaian)' kirareru - kiraremasu - kiraremasen

3. Bentuk spesial, digunakan oleh verba golongan III. Golongan ini merupakan bentuk spesial karena terdiri dari dua verba saja, yaitu suru 'melakukan' dan kuru 'datang'. Perubahannya adalah seperti berikut.

a. Kuru (kimasu) 'datang' - korareru koraremasu - koraremasen

b. Suru (shimasu) 'melakukan' - sareru saremasu - saremasen

Pasif dalam bahasa Jepang saling berhubungan dengan unsur pembentuk kalimat pasif itu sendiri, sehingga jenis pasifnya dapat dibagi menjadi pasif langsung (chokusetsu ukemi), pasif tak langsung (daisansha ukemi), dan pasif kepemilikan (mochinushi ukemi)'. Diatesis pasif (ukemi) berdasarkan situasinya dapat dibagi menjadi beberapa jenis, yaitu:

1. Situasi ketika pembicara tidak ingin menyebutkan siapa yang menjadi pelaku dari sebuah aktivitas verba,

2. Situasi yang menyatakan pembicara merasa lebih dekat dengan orang yang dikenai perbuatan (penderita) daripada pelaku,

3. Situasi yang digunakan untuk menyatakan perasaan gangguan (meiwaku) (Iori, 2001).

Tipe pembentukan konstruksi pasif dalam bahasa Jepang dapat dibagi menjadi dua, yaitu chokusetsu ukemi (pasif langsung) dan kansetsu ukemi (pasif tidak langsung) (Iori and Dkk., 2000:294-295). Selain itu terdapat pasif yang menyatakan pembuatan sesuatu.

\section{Analisis Konstruksi Pasif Bahasa Indonesia}

$\begin{array}{llll}\text { a. } & \text { に } & \text { 大きい } & \text { 桃 } \\ \text { Kawa } & \text { ni } & \text { ookii } & \text { momo } \\ \text { Sungai } & \text { di } & \text { besar } & \text { buah persik }\end{array}$




$\begin{array}{ll}\text { が } & \text { 発見されました。 } \\ \text { ga } & \text { hakken saremashita. } \\ \text { PEM } & \begin{array}{l}\text { ditemukan-LAM } \\ \text { (hakken shimasu) }\end{array}\end{array}$

Artinya:

'Ditemukan buah persik yang besar di sungai.'

Dalam contoh diatesis tersebut memiliki makna diatesis pasif dapat digunakan pada waktu pelakunya tidak menjadi persoalan, maka yang menggantikan posisi subjek adalah benda atau hal tersebut. Dalam diatesis tersebut, ookii momo 'buah persik besar' yang menggantikan posisi subjek dan diikuti oleh verba pasif.

b. 桃太郎

Momotarou

は 村人

NM ORG

wa murabito

SUB penduduk desa

\section{に＼cjkstart褒められました。 \\ ni homeraremashita. \\ oleh dipuji-LAM \\ (homemasu)}

Artinya:

'Momotarou (sudah) dipuji oleh penduduk desa.'

Dalam diatesis pasif bahasa Jepang, penderita ditandai dengan partikel $w a$ dan posisi penderita berpindah ke depan, sedangkan pelaku ditandai dengan partikel $n i$ dan posisi pelaku berada pada sebelum verba pasif.

$\begin{array}{llll}\text { c. ある日、 } & \text { 鬼 } & \text { に } & \text { 村人 } \\ \text { Aruhi, } & \text { oni } & \text { ni } & \text { murabito } \\ \text { Suatu hari } & \text { siluman } & \text { oleh } & \begin{array}{l}\text { penduduk } \\ \text { desa }\end{array}\end{array}$

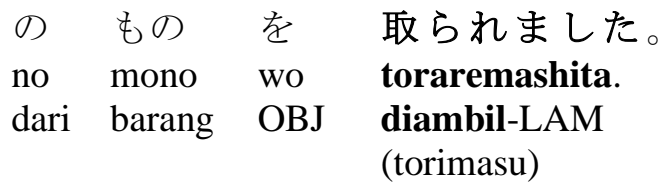

Artinya:

'Pada suatu hari, barang penduduk desa diambil oleh siluman.'
Dalam contoh diatas, penderita yaitu murabito 'penduduk desa' merasakan suatu perasaan yang tidak menyenangkan yang dilakukan oleh oni 'siluman' yang bertindak sebagai pelaku. Kata 'oni' akan diikuti oleh partikel $n i$ sebagai penjelas bahwa kata tersebut merupakan pelaku aksi pada verba. Kata 'oni' akan diikuti oleh verba pasif toraremashita 'diambil-LAM'. Sehingga struktur kalimat pasifnya masih tetap menggunakan pola S-O-P.

$\begin{array}{lcl}\text { d. 村人 } & \text { は } & \text { 桃太郎 } \\ \text { Murabito } & \text { wa } & \text { momotarou } \\ \text { Penduduk desa } & \text { SUB } & \text { NM ORG }\end{array}$

$$
\begin{array}{ll}
\text { を } & \text { 褒めました。 } \\
\text { wo } & \text { homemashita. } \\
\text { OBJ } & \begin{array}{l}
\text { memuji-LAM } \\
\text { (homeru) }
\end{array}
\end{array}
$$

Artinya:

'Penduduk desa (sudah) memuji momotarou.'

$\begin{array}{llll}\text { e. 桃太郎 } & \text { は } & \text { 村人 } & \text { に } \\ \text { Momotarou } & \text { wa } & \text { murabito } & \text { ni } \\ \text { NM ORG } & \text { SUB } & \begin{array}{l}\text { penduduk } \\ \text { desa }\end{array} & \text { oleh } \\ & & \end{array}$

褒められました。
homeraremashita.
dipuji-LAM
(homeru)

Artinya:

'Momotarou (sudah) dipuji oleh penduduk desa.'

Dalam chokusetsu ukemi, penderita yaitu Momotarou 'momotarou' langsung merasakan apa yang dilakukan oleh pelaku yaitu murabito 'penduduk'.

$\begin{array}{llll}\text { f. 桃太郎 } & \text { は } & \text { サル } & \text { に } \\ \text { Momotarou } & \text { wa } & \text { saru } & \text { ni } \\ \text { NM ORG } & \text { SUB } & \text { monyet } & \text { oleh } \\ \text { キビ団子 } & \text { を } & \text { 食べられました。 } \\ \text { kibidango } & \text { wo } & \begin{array}{l}\text { taberaremashita. } \\ \text { kibidango }\end{array} & \text { OBJ } \\ \text { dimakan-LAM } \\ \text { (tabemasu) }\end{array}$


Artinya:

'Kibidango (Momotarou) dimakan oleh monyet.'

Dalam kansetsu ukemi, kibidango 'kibidango' menjadi penderita dalam konstruksi kalimat tersebut karena ia dikenai aksi perbuatan pada verba, sedangkan momotarou 'momotarou' pada kalimat diatas tidak bertindak sebagai penderita secara langsung karena tidak mengalami gangguan akibat kejadian pada verbanya.

\section{g. Bentuk Aktif

$\begin{array}{lrll}\text { サル } & \text { は } & \text { 門 } & \text { を } \\ \text { Saru } & \text { wa } & \text { mon } & \text { wo } \\ \text { Monyet } & \text { SUB } & \text { gerbang } & \text { OBJ }\end{array}$ \\ 吒きました。 \\ tatakimashita. \\ memukul-LAM \\ (tatakimasu) \\ Artinya: \\ 'Monyet (sudah) memukul gerbang'

\begin{tabular}{llll}
\multicolumn{2}{l}{ Bentuk Pasif } & & \\
門 & は & サル & に \\
Mon & wa & saru & ni \\
Gerbang & SUB & monyet & oleh
\end{tabular} \\ 吒かれました。 \\ tatakaremashita. \\ dipukul-LAM \\ (tatakimasu) \\ Artinya: \\ 'Gerbang dipukul oleh monyet'}

Pada contoh kalimat (1) merupakan contoh kalimat transitif sedangkan kalimat (2) merupakan contoh kalimat pasif bahasa Jepang. Disebut chokusetsu ukemi 'bentuk pasif langsung' karena kalimat (2) berasal dari kalimat transitif yang objeknya ditandai dengan partikel wo pada kalimat (1).

$\begin{array}{llll}\text { h. キビ団子 } & \text { は } & \text { ご飯 } & \text { から } \\ \text { Kibidango } & \text { wa } & \text { gohan } & \text { kara } \\ \text { Kibidango } & \text { SUB } & \text { olahan nasi } & \text { dari }\end{array}$

作られました。

\author{
tsukuraremashita \\ terbuat \\ (tsukurimasu)
}

Artinya:

'Kibidango dibuat dari olahan nasi'

Dalam diatesis pasif tersebut yang menyatakan pembuatan sesuatu digunakan partikel kara 'dari' dan tidak menggunakan partikel $n i$ 'oleh'karena pelaku tidak disebutkan.

\section{Perbedaan Konstruksi Pasif Bahasa Indonesia dan Bahasa Jepang}

Dilihat dari urutan struktur pembentuk kalimatnya, bahasa Indonesia dan bahasa Inggris memiliki perbedaa pada peletakkan unsur objek dan predikatnya. Di samping itu, pada pembahasan sebelumnya dapat ditemukan beberapa persamaan dan perbedaan antara bahasa Indonesia dan bahasa Jepang. Persamaan antara konstruksi pasifnya adalah sebagai berikut:

1. Keduanya memiliki pemarkahan morfologis pada pasif, yaitu adanya prefiks $d i$ - untuk bahasa Indonesia dan sufiks (r)areru untuk bahasa Jepang;

2. Keduanya memiliki pemarkah agen, yaitu oleh untuk bahasa Indonesia dan ni, ni yotte, dan kara untuk bahasa Jepang.

Persamaan terhadap adanya pemarkah agen pada kedua bahasa ini dapat merujuk pada fakta bahwa chokusetsu ukemi dapat disejajarkan dengan pasif kanonis dalam bahasa Indonesia. Disamping persamaan dari sisi pemarkahnya, perbedaan pasif bahasa Indonesia dan bahasa Jepang terlihat pada proses afiksasi yang terjadi. Jika dalam bahasa Indonesia, proses afiksasi dalam diatesis pasif terjadi dengan menambahkan prefiks seperti $d i$ - dan ter-, tetapi dalam bahasa Jepang proses afiksasi terjadi dengan menambahkan sufiks agar menjadi sebuah kalimat pasif.

\section{SIMPULAN}

Dari analisis data di atas maka dapat ditarik simpulan sebagai berikut:

\section{Kalimat pasif bahasa Indonesia:}

1. Struktur kalimat bahasa Indonesia memiliki konstruksi dasar Subjek+Objek+Verba, sehingga kalimat aktif maupun kalimat pasif 
dalam bahasa Indonesia mengikuti kaidah konstruksi tersebut. Selain itu, kalimat pasif dalam bahasa Indonesia memiliki penanda yang terlihat pada pemberian afiks sebelum verba. Penambahan Afiks pada verba tersebut antara lain prefiks di-, ter-, ke-, dan klofiks di-kan dan ke-an.

2. Selain adanya afiks sebagai pemarkah konstruksi pasif, terdapat pula peran semantik dari fungsi struktur kalimat pasif yaitu:

a. Subjek dalam konstruksi pasif bukan bertindak sebagai pelaku dari perbuatan, tetapi sebagai sasaran atas perbuatan verba dalam kalimatnya. Peran semantis subjek dalam konstruksi pasif dapat berperan sebagai patient (penderita), penerima atau hasil dari perbuatan yang tercermin pada verba. Unsur pengisi subjek dapat berupa makhluk hidup (animate) atau tak hidup (unanimate).

b. Predikat dalam konstruksi pasif selalu memunculkan imbuhan pasif (di-, ter, ke, di-kan, ke-an).

c. Objek memiliki fungsi sebagai pelaku atas aksi pada verba. Pemarkah 'oleh' diletakkan sebelum objek yang berperan sebagai pemarkah pelaku (bersifat optional).

3. Konstruksi kalimat pasif dalam bahasa Indonesia tetap menggunakan konstruksi dasarnya, yaitu Subjek+Verba+Objek dengan pemberian imbuhan yang beragam seperti berikut.
a. Subjek + Verba [ter-] + (oleh) O
b. Subjek + Verba [ke-] + (oleh) O
c. Subjek + Verba $[$ di-kan $]+\mathrm{O}+\mathrm{Pel}$
d. Subjek + Verba [ke-an]

\section{Kalimat pasif bahasa Jepang:}

1. Struktur kalimat bahasa Jepang memiliki konstruksi dasar Subjek+Objek+Verba, sehingga kalimat aktif maupun kalimat pasif dalam bahasa Jepang selalu mengikuti kaidah konstruksi tersebut.

2. Pemarkah konstruksi pasif dalam bahasa Jepang ditandai dengan munculnya sufiks $\sim$ reru rareru. Sufiks ini merupakan bagian dari salah kelas kata auxiliary verb atau verba bantu.

3. Dalam bahasa Jepang, jenis kalimat pasif dibagi menjadi dua yaitu jenis kalimat pasif langsung dan kalimat pasif tidak langsung. Persamaan konstruksi pasif bahasa Indonesia dan bahasa Jepang terletak pada peran semantic dan fungsi sintaksisnya, yakni subjek dalam kalimat pasif bukan sebagai pelaku tetapi sebagai target atau sasaran dari aksi pada verba. Perbedaan antara konstruksi pasif bahasa Indonesia dan bahasa Jepang muncul pada kehadiran subjek dengan partisipan yang berbeda, dalam hal ini subjek dalam konstruksi pasif bahasa Jepang wajib berupa makhluk hidup. Adanya subjek yang bukan makhluk hidup pada konstruksi pasif bahasa Jepang selalu terdapat dalam bentuk kalimat langsung yang memiliki makna penemuan atau pembuatan sesuatu.

4. Struktur kalimat pasif langsung bahasa Jepang

\begin{tabular}{|c|c|c|}
\hline \multirow{2}{*}{$\begin{array}{l}\text { Kalimat } \\
\text { Pasif } \\
\text { Langsung }\end{array}$} & \multicolumn{2}{|c|}{$\begin{array}{c}\text { Kalimat Pasif Tidak } \\
\text { Langsung }\end{array}$} \\
\hline & $\frac{\text { Verba }}{\text { transitif: }}$ & $\underline{\text { Verba }}$ \\
\hline $\begin{array}{c}\mathrm{S}+[\mathrm{wa}]+\mathrm{O} \\
{[\text { ni }]+\mathrm{V}} \\
\sim \text { reru } \\
\text { [ga }] \\
\sim \text { rareru }\end{array}$ & $\begin{array}{c}\mathrm{S} \text { [wa] + O1 } \\
{[\text { ni] + O2 }} \\
\text { [wo] + V } \\
\sim \text { reru } \\
\sim \text { rareru }\end{array}$ & $\begin{array}{c}\mathrm{S}[\mathrm{wa} / \mathrm{ga}]+ \\
\mathrm{O}[\mathrm{ni}]+\mathrm{V} \\
\sim \mathrm{reru} \sim \mathrm{rareru}\end{array}$ \\
\hline $\begin{array}{c}\mathrm{S}+[\mathrm{wa}]+ \\
\mathrm{V} \sim \mathrm{reru} \\
\quad[\mathrm{ga}] \\
\sim \text { rareru }\end{array}$ & & $\begin{array}{c}\mathrm{O}[\mathrm{ni}]+\mathrm{V} \\
\sim \operatorname{reru} \sim \text { rareru }\end{array}$ \\
\hline $\begin{array}{l}\mathrm{O}[\mathrm{ni}]+\mathrm{V} \\
\sim \text { reru } \sim \text { rareru }\end{array}$ & & \\
\hline
\end{tabular}

\section{DAFTAR PUSTAKA}

Alisjahbana, S. T. (1983). Tata Bahasa Baru Indonesia. Dian Rakyat.

Dardjowidjojo, S. (1986). "Benang Pengikat dalam Wacana." Dalam Bambang Kaswanti Purwo (ed). In Pusparagam Linguistik dan Pengajaran Bahasa. Arcan.

Elson, B. \&, \& Pickett, V. (1962). An Introduction to Morphology and Syntax. Summer Institute of Linguistics.

Iori, I. (2001). Atarashii Nihongogaku Nyuumon (Kotoba no Shikumi o Kangaeru). Suriiee Nettowaku.

Iori, I., \& Dkk. (2000). Shokyuu wo Oshieru 
KONTRASTIVITAS DIATESIS PASIF BAHASA INDONESIA DAN BAHASA JEPANG ...

Hito no Tame no Nihongo Bunpou Hando Bukku. 3A Corporation.

Mees, C. A. (1969). Tata Bahasa dan Tata Kalimat. University Malaya Press.
Slametmuljana. (1969). Kaidah Bahasa Indonesia. Nusa Indah.

Verhaar, J. W. . (1996). Asas-asas Linguistik Umum. Gadjah Mada University Press. 